\section{Dose and Timing of Brushing to Control Excessive Hypocotyl Elongation in Cucumber Transplants}

\author{
Thomas Björkman
}

AdDitional INDEX WORDS. stretching, mechanical conditioning, height control, C ucumissativus

Summary. Brushing is an effective method to control hypocotyl elongation in cucumbers (C ucumissativus $L$. 'Turbo') grown in plug trays for transplanting. The amount of daily brushing and the number of days to brush for best performance was determined. T reatment with 10 strokes per day for the 4 days of maximal hypocotyl elongation was sufficient to reduce final hypocotyl length by $25 \%$. M ore brushing did not meaningfully reduce elongation further. Inhibition of dry weight gain, which is detrimental, was minor $(<10 \%)$ compared with the height control achieved. D espite seasonal differences in absolute elongation, the effects of brushing were the same.

S tretching is the excessive elongation of stems during the production of high-density transplants. $O$ verly long stems make transplants susceptible to injury during handling and after transplanting. $M$ echanical stimulation has been successfully applied to control stretching and improve posttransplant performance in cucumbers (Latimer and Beverly, 1994), squash (C ucurbita pepo

D epartment of $\mathrm{H}$ orticultural Sciences, $\mathrm{N}$ ew York State Agricultural Experiment Station, Cornell U niversity, Geneva, NY 14456

The skilled technical assistance of Karen Pearson is gratefully acknowledged. This research was supported by $\mathrm{H}$ atch project NY.G623-512. The cost of publishing this paper was defrayed in part by the payment of page charges. Under postal regulations, this paper must hereby be marked adverti sement solely to indicate this fact.
L.) (L atimer and Beverly, 1994), tomatoes ( Lycopersicon esculentum M ill.) (Garner and Björkman, 1996; L atimer and Beverly, 1993; L atimer and Thomas, 1991), eggplant (Solanum melongena var. esculentum $L$. N ees.) (Baden and Latimer, 1992) aster [Callistephuschinensis(L.) N ees], petunia(Petunia Juss.) (Autio et al. 1994) and pansies (Viola tricol or L.) (Garner and Langton, 1997). Brushing is the preferred method for mechanical conditioning (L atimer, 1998). Transplant growers in the northeastern U .S. frequently request information from extension about using this technique to control hypocotyl elongation in cucumbers. For this crop, there is no dose recommendation available. The minimum treatment to obtain height control is the economically important parameter. Also, the treatment must avoid injury, which can occur in cucumbers (L atimer et al., 1991). The detrimental side effects of mechanical treatment can be limited if the minimum effective stimulation is applied (Garner and Björkman, 1996). This paper reports the conditions that produce the optimal height control of cucumbers with the minimum treatment and injury.

\section{Materials and methods}

CONDITIONS FOR PLANT GROWTH. 'Turbo' cucumber seeds were sown in a peat-vermiculite growing medium (Boodley and Sheldrake, 1977) containing $0.35 \mathrm{~N}-0.15 \mathrm{P}-0.15 \mathrm{~K} \mathrm{~kg} \cdot \mathrm{m}^{-3}$ $\left(0.6 \mathrm{~N}-0.26 \mathrm{P}-0.25 \mathrm{~K} \mathrm{lb} / \mathrm{yd}^{3}\right)$. The plastic 50 -cell plug flats (Landmark, Akron, O hio) had cells were $44 \mathrm{~mm}$ (1.75 inches) square and $66 \mathrm{~mm}(2.5$ inches) deep holding $66 \mathrm{~mL}$ ( 4 inches ${ }^{3}$ ). $\mathrm{N}$ ondwarf hybrid varieties like Turbo are especially prone to stretching. The plants were raised in a greenhouse without supplemental lighting, with two sowing dates: 9 and 28 Apr. 1998. The second planting grew when the risk of stretching is highest due to frequent high temperaturesand cloudy days. Thegreenhousetemperaturewas maintained at a minimum of $18 / 22$ ${ }^{\circ} \mathrm{C}\left(65 / 73^{\circ} \mathrm{F}\right)$ (night/ day). The daytime maximum was higher, up to 32 ${ }^{\circ} \mathrm{C}\left(90^{\circ} \mathrm{F}\right)$ on sunny days. Plants were irrigated each morning and, if necessary, in the afternoon. Supplemental fertilization was included with the irrigation on days 7,14 , and 18 using soluble fertilizer at $100 \mathrm{~N}-44 \mathrm{P}-83 \mathrm{~K}$ ppm. Plants were grown for $7 \mathrm{~d}$, until 


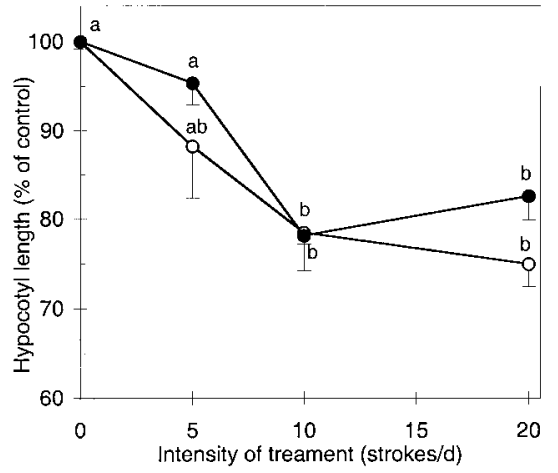

Fig. 1. Effect of the number of daily strokes on hypocotyl elongation in cucumber seedlings. T he treatments were applied for $10 \mathrm{~d}$. 0 pen circles = early-season trial [ $100 \%=63 \mathrm{~mm}$ (2.5 inches) ]. C losed circles = lateseason trial $[100 \%=117 \mathrm{~mm}(4.6$ inches) ]. Points with different letters are significantly different by T ukey's pairwise comparisons test $(P<0.05)$. $B$ ars are the standard error of the mean; $n=4$ flats.

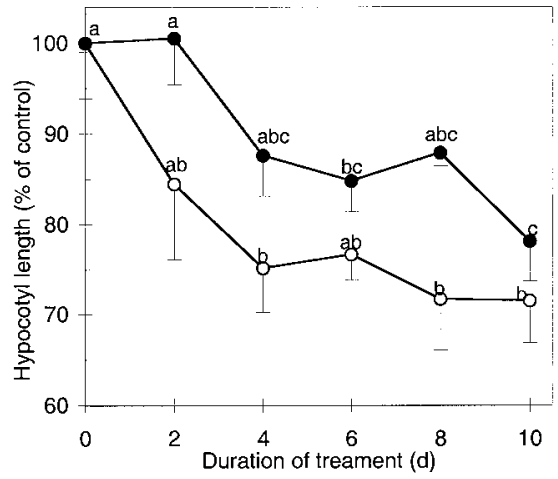

Fig. 2. Effect of the duration of brushing treatments on hypocotyl elongation in cucumber seedlings. The seedlings were brushed with 10 strokes per day. 0 pen circles = earlyseason trial $[100 \%=74 \mathrm{~mm}(2.9$ inches) ]. C losed circles = late-season trial $[100 \%=117 \mathrm{~mm}$ (4.6 inches)]. Points with different letters are significantly different by T ukey's pairwise comparisons test $(P<0.05)$. $B$ ars are the standard error of the mean; $n=4$ flats.

the cotyledons had unfolded before being brushed thefirst time. Thisisthe earliest that the canopy is uniform enough for brushing.

EXPERIMENTAL TREATMENTS. Brushing was performed by stroking back and forth with a near-vertical piece of Styrofoam held gently to cause the tops of the plants to move $\approx 2 \mathrm{~cm} \mathrm{(1}$ inch) sideways. The experimental units were flats of 50 seedlings. There were four flats per treatment with all the flats distributed in a completely randomized design on the greenhouse bench. The experiment to determine the effect of daily intensity of brushing consisted of $0,5,10$, or 20 strokes applied each morning for 10 days. The experiment to determine the effect of duration of brushing treatment consisted of treating the plants with 10 strokes/ d for $0,2,4,6,8$, and $10 d$, all beginning on the same day. The plants were harvested $12 \mathrm{~d}$ after brushing began, at which time hypocotyl elongation was complete.

For the intensity experiment, the cotyledon length, leaf length and dry mass were measured on 10 seedlings per flat. In addition, the lengths of 15 hypocotyls per flat were measured. A calibration curve was created for cotyledon and leaf area using an Agvision leaf area meter ( $D$ ecagon Devices, Pullman, Wash). For cotyledons, area $=0.43 \times$ length $^{2}$, and for leaves, area $=$ $0.90 \times$ length $^{2}$. For the duration experiment, the hypocotyl length was measured on 10 randomly selected seedlings per flat each day. At the end of the experiment, cotyledon length and leaf length of 10 seedlings and the dry mass of 20 shoots were measured for each flat.

$\mathrm{H}$ ypocotyl elongation responded nonlinearly to treatment intensity and duration ( $P<3 \%$ ), so Tukey's pairwise comparisonswere used to indicate significant differencesin hypocotyl length. The statistical analysisfor possible detrimental effects (reduced leaf or cotyledon length, or reduced dry mass) consisted of determining whether the treatment had a significant negative effect on the response using simple linear regression. There was no interaction between trials, so the tests were performed on the pooled data with trials as a blocks.

\section{Results and discussion}

DAILY BRUSHING INTENSITY. Stretching was maximally inhibited by 10 strokes/ d (Fig. 1). As with tomatoes (Garner and Björkman, 1996), elongation is highly responsive to small doses of mechanical stimulation, while further increasing the daily dose had no effect.

Brushing duration. H ypocotyls were progressively shorter with a greater number of days that the seedlings were brushed. The first $4 \mathrm{~d}$ had the greatest effect (Fig. 2). H ypocotyl elongation followsa sigmoidal pattern
(Fig. 3), so elongation is best inhibited during the rapid elongation phase, which lasts $\approx 7 \mathrm{~d}$. Therefore, brushing should begin asso on as the cotyledons have unfolded and before the first leaf begins to expand. Continuing brushing after hypocotyl elongation has ceased hasno valuefor producing shortstemmed transplants. Elongation ceased by the time the second leaf was visible (day 10 on Fig. 3). Thus, the effective period for brushing is $\approx 6$ to 8 $d$ long. N early the full effect can be obtained by brushing on 4 of these days.

Detrimental effects. Leaf area was not markedly affected by this mechanical treatment. Reduction of leaf or cotyledon area would reduce the amount of photosyntheticarea, thereby reducing the transplant's potential for carbon assimilation. The treatment is applied directly to the cotyledons and, later, the first leaf. Therefore a reduction in size might be expected. The comparison was made in both early and late experiments, as well as in duration and intensity experiments.

Linear regression showed a small but significant $(P<0.05)$ reduction in cotyledon and leaf length as well as biomass in response to increasing the daily dose (Fig. $4 a$ and $\mathrm{C}$ ). From the regression equation, a dose of 10

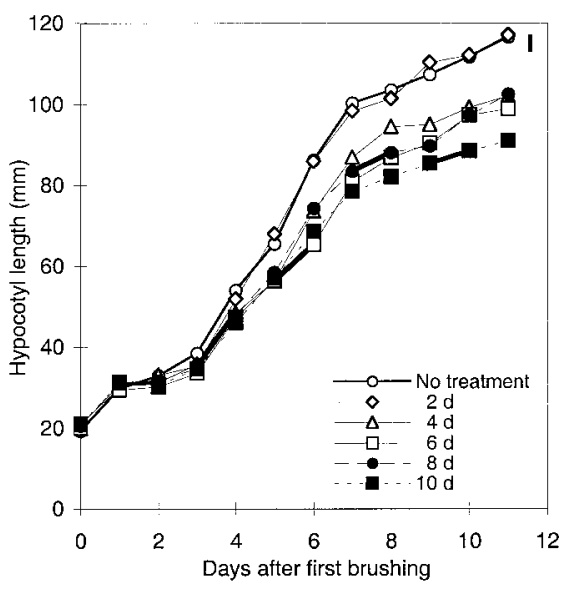

Fig. 3. Stem elongation of cucumber hypocotyls while receiving brushing treatment ( $25.4 \mathrm{~mm}=1.0$ inch). The legend indicates the duration of the brushing treatment. A heavy line is used to indicate the last day of brushing for individual curves. The standard error is indicated by the vertical line in the upper right corner. These data are from the late trial, the early trial had qualitatively the same response. 


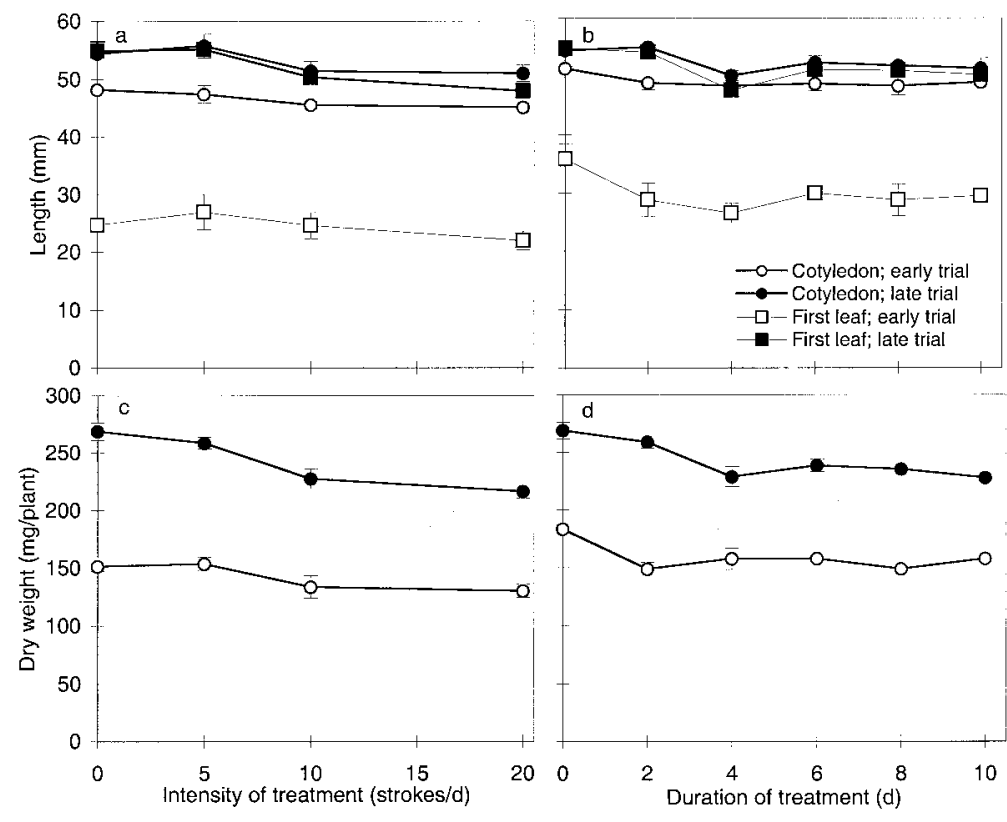

Fig. 4. D etrimental effects of brushing on cucumber seedlings. E ffect of daily intensity of brushing ( $a$ and $c$ ) and the number of days treated ( $b$ and d) on the length $(25.4 \mathrm{~mm}=1.0$ inch) of cotyledons and first leaf (a and $b$ ) and on shoot dry weight $(28,350 \mathrm{mg}=1.0 \mathrm{oz})$ ( $\mathrm{c}$ and d). All data were collected $11 \mathrm{~d}$ after the first brushing treatment. Vertical bars are the standard error.

strokes/ d is predicted to make the cotyledons $4 \%$ shorter, the leaves $10 \%$ shorter and the plants $12 \%$ lighter at $19 \mathrm{~d}$. The response to increasing treatment duration was similar, though most of the difference was between controls and any treatment (Fig. 4b and d). The leaf length was affected by brushing that occurred when that leaf was $<5 \mathrm{~mm}$ (0.4 inches) long (before day 4). Surprisingly, additional brushing while the leaf was expanding had no further effect (Fig. 4b). A duration of $6 \mathrm{~d}$ is predicted to make the cotyledons only $3 \%$ shorter, the leaves $7 \%$ shorter and the plants $9 \%$ lighter. The undesirablegrowth inhibition wasconsistently smaller than the $25 \%$ reduction in hypocotyl length obtained by brushing.

Plant damage occurred only in the 20-stroke/ d treatment, and it was rare. In this treatment, $5 \%$ of the seedlingstipped over, though the hypocotyls did not break. This malady ap- peared to affect only seedlings with a poorly developed radicle. There was no damage in other treatments.

U ndesirable side effectshave been reported with greater treatment intensity. C ucumber transplantstreated with 80 strokes/ d at a comparable growth stage showed a similar reduction in stem length, but leaf area was reduced by $30 \%$ to $40 \%$ and dry weight by $15 \%$ to $25 \%$ (L atimer and Beverly, 1994). The same treatment, begun once the second true leaf was visible, still reduced leaf area, dry weight and subsequent yield (L atimer et al., 1991). The treatment indicated in the present paper is only 1/ 24 as much; only hypocotyl elongation was meaningfully inhibited. No damage to the seedlings should occur with the optimal dose of 10 strokes.

The response to varying the amount of brushing in cucumbers was qualitatively similar to that in tomatoes (Garner and Björkman, 1996), aster and petunia (Autio et al., 1994). I expect it to be similar in all rapidly elongating stems that are prone to stretching. The common features are that the response to increasing the daily dose is easily saturated, and the minimum daily dose to saturate the response is mild. In addition, the response is greater when plants are brushed for more days. Further evidence of a consistent responseto brushing is that the best brushing regimen for cucumber transplant production was the same in the two trials, even though longer, warmer days made the seedlings in the later trial nearly twice as tall.

These results indicate that the optimal brushing treatment to limit stretching in cucumber transplants is to begin brushing when the cotyledons have unfolded, and to apply 10 strokes each morning for the following $6 \mathrm{~d}$. This optimal treatment should reduce elongation $\approx 25 \%$ with no detrimental effect.

\section{Literature cited}

A utio, J., I . Voipo, and T. Koivunen. 1994. Responses of aster, dusty miller, and petunia seedlings to daily exposure to mechanical stress. H ortScience 29:1449-1452.

Baden, S.A. and J.G. Latimer. 1992. An effective system for brushing vegetable transplants for height control. H ortT echnology 2:412-414.

Boodley, J.W. and R. Sheldrake. 1977. Cornell Peat-Lite mixes for commercial plant growing. Cornell U niv. Plant Sci. Info. Bul. 43.

Garner, L.C. and T. Björkman. 1996. M echanical conditioning for controlling excessive elongation in tomato transplants: Sensitivity to dose, frequency, and timing of brushing. J. Amer. Soc. H ort. Sci. 121:894-900.

Garner, L.C. and F. Langton. 1997. B rushing pansy (Viola tricol or L.) transplants: A flexible, effective method for controlling plant size. Scientia H ort. 70:187-195.

Latimer, J.G. 1998. Mechanical conditioning to control transplant height. H ortT echnology 8:529-534.

Latimer, J.G. and R.B. Beverly. 1993. $M$ echanical conditioning of greenhousegrown transplants. HortT echnology 3:412-414.

Latimer, J.G. and R.B. Beverly. 1994. Conditioning affects growth and drought tolerance of cucurbit transplants. J. A mer. Soc. H ort. Sci. 119:943-948.

Latimer, J.G., T. Johijima, and K. H arada. 1991. The effect of mechanical stress on transplant growth and subsequent yield of four cultivars of cucumber. Scientia H ort. 47:221-230.

Latimer, J.G. and P.A. Thomas. 1991. Application of brushing for growth control of tomato transplants in a commercial setting. H ortTechnology 1:109-110. 